\title{
Las Naciones Unidas y los Estados Unidos: antes y después del 11 de septiembre de 2001
}

\author{
Juan Gabriel Valdés
}

Representante de Chile ante las Naciones Unidas

Conferencia dictada ante el Consejo Chileno de Relaciones Internacionales, Santiago de Chile, 13 de marzo de 2002.

Las Naciones Unidas son más que un conjunto de instituciones, de resoluciones de sus órganos o de tratados internacionales. En la actividad de la Asamblea General o del Consejo de Seguridad, en la vida de los Comité, pero también en los encuentros informales de los diplomáticos, así como en la energía internacional que es tan propia de la ciudad de Nueva York, se articula un universo de opiniones y actitudes que permiten una visión privilegiada de la situación internacional. Es verdad que ellas reflejan mucho más que lo que la organización logra incorporar en sus trabajos, y mucho más que aquello sobre lo cual está en condiciones de decidir, pero hacen del edificio azul una caja de resonancia de las alianzas y los conflictos que atraviesan el sistema internacional actual. Es desde esta base de observación que me interesa reflexionar sobre la relación entre la organización y el principal de sus miembros, los Estados Unidos, y la manera como la propia complejidad de esa interacción obliga a las Naciones Unidas a una reforma de sus formas de organización y de trabajo, si es que de veras desea cumplir las tareas que le señala la Carta.

El 11 de septiembre recién pasado pareció indicar, inicialmente, un cambio en la relación entre las Naciones Unidas y los 
Las Naciones Unidas y los Estados Unidos
Estados Unidos. Tras un largo período de desavenencias y tensiones, el horrible atentado estableció una oportunidad de confluencia y concertación. La Asamblea General y el Consejo de Seguridad otorgaron, en históricas resoluciones, un alto nivel de respaldo a Washington: probablemente el mayor otorgado nunca a cualquier nación en la historia de la organización. Por su parte, el gobierno del presidente Bush adoptó una serie de medidas destinadas a "construir confianza" y a movilizar a la organización en apoyo a la guerra contra el terrorismo. En ese marco, muchos abrigaron la esperanza de un giro histórico. Se consideró que, con el atentado, una nueva conciencia de los riesgos de la globalización, del carácter complejo y global de la amenaza y de la necesaria complejidad de la respuesta, pero sobre todo, la actitud decidida de las Naciones Unidas para enfrentarlo, podría dejar atrás, o al menos moderar, el 1lamado "unilateralismo" de los Estados Unidos. Pero este período de confluencia ha tendido recientemente a deteriorarse. A seis meses del atentado, ese termómetro de la opinión internacional que son los pasillos y las comisiones de la Asamblea General y los salones de las misiones permanentes, registran nuevamente una gran perplejidad acerca del futuro de la relación y un alto grado de escepticismo acerca de lo que puede hacerse para mantener un marco de cooperación constructivo y recíprocamente respetuoso entre las Naciones Unidas y el principal de sus Estados miembros.

\section{UN PASADO DE CONFLICTOS}

Debe recordarse que, en el pasado reciente, el conflicto había sido más la constante que la excepción. Durante los últimos años de la guerra fría, pero ya desde la década de 1960, la Asamblea General enfrentó a los Estados Unidos con proyectos ideológicos tales como el Nuevo Orden Económico Internacional, que pretendía entregar a los Estados un mayor control sobre el proceso de transnacionalización, o el llamado Nuevo Orden Informativo Internacional, que perseguía incrementar el poder de los gobiernos en el manejo de la información.

Por esos años se aprobaron por grandes mayorías resoluciones que irritaron profundamente a la opinión pública y política de los Estados Unidos, muy especialmente aquella que igualaba 
el sionismo con el racismo. En un marco de tensiones internacionales propias del conflicto con la Unión Soviética, estas actitudes alienaron gravemente a grupos importantes del país y facilitaron la tarea de un mundo conservador norteamericano que heredaba una antigua tradición de aislacionismo y defensa a ultranza de la soberanía.

Más tarde, al desmoronarse el imperio soviético, la idea de Washington, pero también del Secretario General Boutros Ghali, de utilizar a las Naciones Unidas para evitar la participación de fuerzas norteamericanas en situaciones peligrosas, o complementar acciones militares no resueltas, condujo a catástrofes como la intervención norteamericana en Somalia -de la cual se culpó injustamente a las Naciones Unidas-o a la inactividad ante el genocidio en Rwanda -en que la acción del Consejo de Seguridad fue vetada por Estados Unidos- y a una guerra en Yugoslavia, en que la indecisión inicial europea y norteamericana debilitó más aún la imagen de la organización.

Desde entonces, la acción de la Asamblea General se ha debilitado particularmente. Tras un período inicial en que la Asamblea tuvo al proceso de descolonización como su principal tarea y en que los debates de la guerra fría le dieron un rol que a menudo llevó a opacar el del Consejo, la Asamblea General languidece hoy día, recargada por una agenda abigarrada que la ha conducido a extraviar su rol esencial. Es significativo que las grandes conferencias, tales como la del sida y la próxima sobre financiación del desarrollo, se realizan al margen de la agenda de la Asamblea General. Con temas de escaso interés para la comunidad internacional, esta agenda se examina en medio de la indiferencia no sólo de la opinión pública, sino, lo que es peor, de los propios Estados miembros, contribuyendo a difundir una idea de ineficacia e irrelevancia del principal órgano de la organización.

En este marco, y especialmente a partir del fin de la guerra fría, las críticas norteamericanas a las Naciones Unidas tendieron a multiplicarse. El rechazo al multilateralismo se expresó particularmente en las filas republicanas y muy especialmente en el Congreso, donde la figura del senador Jesse Helms encarnó las posturas que desde entonces serían conocidas como unilateralistas. En efecto, mientras que en los últimos años el Ejecutivo de Washington adoptó la iniciativa de promover proyectos multilaterales, 
Las Naciones Unidas y los Estados Unidos.

tales como el Tratado sobre el Derecho del Mar, el Tratado de Proscripción de los Ensayos Nucleares, el Tratado contra las Minas Antipersonales, la Corte Penal Internacional, el Protocolo de Kyoto sobre el cambio climático, el Tratado contra las Armas Químicas, el Tratado contra las Armas Pequeñas, entre otros, el Congreso norteamericano los rechazó o los postergó indefinidamente.

$\mathrm{Al}$ vencer George Bush en las últimas elecciones y producirse el rechazo a la Corte Penal Internacional, el protocolo de Kyoto y el Tratado contra las Armas Pequeñas, el pesimismo sobre la relación entre las Naciones Unidas y Washington cundió en la organización. Su victoria confirmó lo que el Economist definía como un "unilateralismo paralelo": "la voluntad de acompañar en los acuerdos internacionales sólo en la medida en que sirven a sus propósitos inmediatos, para luego sobrepasar sus límites todas las veces que no les son útiles". O, como afirmara aún de manera más categórica el escritor Michael Ignatieff: "Los Estados Unidos son unilateralistas cuando quieren y multilateralistas cuando deben"1.

El intento del Congreso norteamericano de legislar para el resto del mundo e imponer sanciones incluso cuando sus aliados no estaban dispuestos a seguirlas, como en aquéllas contra Cuba e Irán, fueron un ejemplo más de esta actitud. Si a esto se agrega que, a pesar de las demandas de la Asamblea General y del propio secretario Kofi Annan de que se incremente la ayuda actual para el desarrollo, la ayuda exterior de los Estados Unidos pasó de $0.3 \%$ del PNB en los años setenta, a 0.1 del PNB en la actualidad, o que mantuvieron durante varios años una deuda con las Naciones Unidas que superó los mil millones de dólares, se entiende bien el pesimismo de la organización respecto de su relación con la superpotencia. En una definición como la que hace el senador Jesse Helms, el rol de las Naciones Unidas se ve drásticamente reducido: "las Naciones Unidas podrán ser un instrumento útil para el rol global de los Estados Unidos, pero si pretenden establecerse como la autoridad moral en el centro de un nuevo orden internacional... entonces está pidiendo una confrontación o bien, provocando la salida de los Estados Unidos de la organización"2.

1 "Tests, Between Concert and Unilateralism", The National Interest, No66, Winter 2001/02, pág. 8.

${ }^{2}$ Helms, Jesse. "American Sovereignty and the UN", The National Interest, Winter 2000/01, pág. 34. Citado en Joseph S. Nye, ob.cit. 
Durante el período previo a la elección, alguien tan importante para la nueva administración como Condoleezza Rice, había criticado a los demócratas por subordinar los intereses de los Estados Unidos a "los intereses de una comunidad internacional ilusoria", o por creer "que el apoyo de varios Estados, o aún mejor, de instituciones como las Naciones Unidas, es esencial al uso legítimo del poder". La nueva administración republicana, en cambio, comprendía que "los acuerdos multilaterales y las instituciones no pueden ser un fin por sí mismos"3.

\section{LAS PRIMERAS REACCIONES}

No podía ser sino con esperanza, por lo tanto, que muchos miembros de la organización acogieron las primeras señales que el gobierno de Washington envió a Naciones Unidas inmediatamente después del atentado. El primer discurso del presidente Bush ante el Congreso, y algunas señales concretas como la rápida aprobación por el Senado de los fondos destinados a Naciones Unidas, así como el nombramiento de un nuevo embajador, John Negroponte, o el cambio de opinión del Departamento del Tesoro respecto de los llamados paraísos fiscales, entre otras señales, parecieron indicar un cambio importante en la orientación original. Las palabras del presidente Bush, pocos días después del atentado, parecían señalar, en verdad, un cambio de orientación: "Así como Pearl Harbor despertó a este país de la noción de que podíamos de algún modo evitar el llamado al deber y defender la libertad en Europa y Asia durante la Segunda Guerra Mundial, así también debería este ataque sorpresivo borrar el concepto existente en algunos sectores de que América puede ir de alguna manera sola en la lucha contra el terrorismo, o en cualquier otra $\operatorname{cosa}^{34}$.

El 18 de octubre, el secretario de Estado, Colin Powell decía: "ya nadie nos dice unilateralistas. Somos tan multilaterales que el chequeo de cada cual y de cada uno me tiene ocupado 24 horas".

${ }^{3}$ Rice, Condolezza. "Campaign 2000 -Promoting the National Interest", Foreign Affairs, Vol. 79, January/February 2000, pág. 47. Citada en Stewart, Patrick. "Don't Fence Me In, The perils of Going It Alone", World Policy Journal, Vol. XVIII, No 3, Fall 2001, pág. 2.

${ }^{4}$ Bush citado en The New York Times, September 19, 2001. Reproducido en Joseph Nye, ob.cit., pág. 5. 
Las Naciones Unidas Y pocas semanas después, ante la Asamblea General, el mismo y los Estados Unidos Powell hablaba de la necesidad de combatir el terrorismo dentro de las fronteras de cada país, a través de programas de democratización, de prevención de conflictos, de alivio de la pobreza, de salud y educación. Y se refería a la crisis en África y a los problemás de "humillación" no resueltos, provocados por la no creación de un Estado Palestino, como elementos que contribuían al cultivo del terrorismo. Éste era, sin duda, el discurso que las Naciones Unidas querían escuchar.

En ese período, el Consejo de Seguridad y la Asamblea General aprobaron resoluciones que otorgaban el más pleno apoyo a los Estados Unidos y comprendían las más drásticas medidas, incluida la autorización para el uso de la fuerza, para apoyar su esfuerzo contra el atentado. Porque, si bien la resolución 1368, aprobada el 12 de septiembre, no se basaba en el Artículo 39, que autoriza el uso de la fuerza para restablecer la paz y la seguridad internacionales, ella abría la posibilidad de imponer "el derecho de autodefensa ante un ataque armado", figura contemplada en el Artículo 51 de la Carta. Es importante recalcar que estas decisiones no hallaron oposición sino, al contrario, un cuadro de cooperación muy extendida. Reflejando el espíritu común, el Secretario General, Kofi Annan, en su discurso ante la Asamblea General, declaraba que: "La comunidad internacional se define no sólo por lo que está a favor, pero también por aquello contra lo cual se opone. Las Naciones Unidas deben tener el coraje para reconocer que así como hay objetivos comunes, hay también enemigos comunes. Para derrotarlos, todas las naciones deben unir esfuerzos... Las Naciones Unidas tienen un rol único para avanzar en este esfuerzo. Provee el foro necesario para construir una coalición universal y puede otorgar una legitimidad global para la respuesta de largo plazo al terrorismo. Las convenciones de las Naciones Unidas proveen desde ya un marco legal para muchos de los pasos que deben enfrentarse para erradicar el terrorismo -incluyendo la persecución de los delincuentes y la supresión del lavado de dinero-"s.

En su resolución, el Consejo de Seguridad instaba a todos los

5 Annan, Kofi A. "Fighting Terrorism on a Global Front", The New York Times, viernes 21 de septiembre de 2001. 
Estados a "que colaboren con urgencia para someter a la acción de la justicia a los autores, organizadores y patrocinadores de estos ataques terroristas y subraya que los cómplices y los autores, organizadores y patrocinadores de estos actos y los responsables de darles apoyo o asilo deberán rendir cuenta de sus hechos"6. Declaraba, igualmente, "que está dispuesto a tomar todas las medidas necesarias para responder a los ataques terroristas perpetrados el 11 de septiembre de 2001 y para combatir el terrorismo en todas sus formas"7.

Pocos días después, el Consejo aprobaba la resolución 1373, en la que además de reiterar el carácter de amenaza a la paz y la seguridad intemacionales del terrorismo y de reafirmar la necesidad de luchar por todos los medios en su contra, decidía que todos los Estados "prevengan y repriman la financiación del terrorismo". La extensa y detallada resolución, una de las más ambiciosas jamás aprobadas por Naciones Unidas, legislaba en los hechos a cuenta de los Estados miembros, señalando detalladamente las medidas destinadas a prevenir los actos terroristas, la forma de persecución y el enjuiciamiento de los responsables y la cooperación a la que se obligaban todos los Estados para luchar contra el flagelo.

Difícilmente, en la historia de las Naciones Unidas, se había dado un respaldo legal más efectivo a una nación agredida. El Comité contra el Terrorismo, creado por la resolución, se obliga a supervisar su cumplimiento por los Estados miembros, de los que requiere informes sobre los cambios realizados en sus legislaciones internas con el propósito de ponerla en práctica.

\section{EL NUEVO ENEMIGO}

Es importante destacar que la resolución y también las acciones derivadas de ella reflejan un concepto del enemigo terrorista que subraya la nueva naturaleza globalizada de su acción; asumen la desagregación de sus componentes; remarcan, en suma, el carácter no estatal de la amenaza.

\footnotetext{
${ }^{6}$ Naciones Unidas, Consejo de Seguridad S/RES/1368 (2001).

${ }^{7}$ Ibid.
} 
Las Naciones Unidas y los Estados Unidos
Esto tiene suma importancia, porque hace evidente que sus redactores comprendían perfectamente lo que había querido decir el vicepresidente norteamericano Dick Cheney, al definir en CNN a Al Qaeda como un "internet chat room". En esa perspectiva, el nuevo enemigo terrorista, transformado en amenaza global, fluye como circulan el capital o la información, desplegándose a través de las sociedades, tanto islámicas como cristianas, desarrolladas como en desarrollo, por lo que la cooperación internacional y el control estricto de sus flujos es de responsabilidad general. La falla de un actor representa, por lo tanto, la inseguridad de todos. La necesidad de una acción multilateral era, entonces, una precondición política esencial para el éxito.

Tal como se afirmara repetidamente en esos días, sólo una alianza muy amplia, a la que nuevos aliados fueran incorporados, podía dar cuenta de la magnitud del desafío. Pero esa visión, que reflejaba perfectamente la forma en que las Naciones Unidas perciben y deben enfrentar el problema, y que coincidía exactamente con las primeras reacciones de Washington, no fue la que aparecería primando, un poco más tarde en el gobierno de los Estados Unidos.

Desde los primeros éxitos norteamericanos en la guerra contra los talibanes, hasta el ya famoso discurso del presidente Bush sobre "el eje del mal", que establece la doctrina del "conmigo o contra mí", se produce una bifurcación en las perspectivas de la guerra antiterrorista. Por una parte, la decisión de la administración Bush de tomar distancia ante la agudización del conflicto entre Israel y los palestinos enfría notablemente la reacción inicial solidaria hacia Washington de los aliados árabes de los Estados Unidos. Éstos han percibido siempre dicho conflicto en el origen no sólo del terrorismo, sino de la desestabilización de sus propios regímenes políticos. Por la otra, y de manera no suficientemente observada por los analistas internacionales, en su nuevo discurso ante el Congreso sobre el estado de la Unión, el presidente Bush modifica la definición original del enemigo terrorista globalizado, agregando ahora uno diferente: "los países que desarrollan armamento de destrucción masiva", entre los que identifica especialmente a Irak, Irán y Corea del Norte. De este modo, la "agenda militar pendiente con Irak" vuelve al escenario como primera prioridad, de una manera que para muchos no potencia 
sino que dificulta la lucha antiterrorista. Además, la inclusión de Irán en la lista de enemigos desecha, en forma incomprensible para muchos, los esfuerzos de un país cuya participación en la estabilización de Afganistán parecía indispensable. En cuanto a Corea del Norte, su alusión debilita seriamente los esfuerzos de reconciliación y las negociaciones que desarrolla Corea del Sur con su vecino, con pleno conocimiento de los Estados Unidos.

Las reacciones europeas ante el discurso sobre "el eje del mal" fueron, como sabemos, particularmente críticas. Hubert Vedrine calificó el discurso de superficial; Joshka Fisher criticó duramente las palabras de Bush y la actitud que ellas reflejaban; el comisario europeo Chris Patten declaró que, precisamente por ser amigos de los Estados Unidos, los europeos tenían dificultades para aceptar "el impacto de una grandiosa inocencia y de un sentido magnífico de autoconfianza e invulnerabilidad", como el reflejado por las palabras de Bush; mientras que Johannes Rau, el conservador alemán, previno que "el éxito de acciones futuras, tanto económicas como políticas, no radica en el aislacionismo o en (...) decisiones solitarias, especialmente cuando se refiere a decisiones militares" (The New York Times, sábado 23 de febrero de 2002, pág. A8).

En Naciones Unidas fue visible el impacto en los países islámicos y, muy especialmente, en los afectados. Pero, para muchos, el retorno aparente a las actitudes unilaterales ponía en riesgo la coalición antiterrorista y señalaba la primacía de una visión militarista que perdía de vista las necesidades políticas de la guerra contra el nuevo enemigo global.

¿A qué se debía este aparente cambio de actitud? Muchos apuntaron al éxito fulminante de la guerra contra Al Qaeda y los talibanes y a la preponderancia que, como resultado, había adquirido el Pentágono en las definiciones internas del aparato de política exterior de Washington. La abrumadora superioridad tecnológica y el celo exhibido por realizar la tarea militar sin más que una intervención muy secundaria de sus aliados, abrían una perspectiva de "reformulación" del escenario regional en el Medio Oriente y el Asia Central, que ciertamente no requería de una "multilateralización" de las acciones militares y las gestiones diplomáticas. El éxito militar en Afganistán conlleva, al menos en este período, la victoria al interior del gobierno de la visión del 
Las Naciones Unidas Pentágono y del equipo construido en torno a la figura de su sey los Estados Unilos cretario, Donald Rumsfeld.

Como es sabido, sin embargo, está en la naturaleza del sistema de toma de decisiones de Washington que ninguna de estas "victorias" es definitiva y que no obligan necesariamente a todos los actores involucrados en la formulación e implementación de políticas a un alineamiento riguroso.

En las semanas que siguieron al discurso, fueron muchos, incluido el propio George W. Bush, quienes emprendieron acciones destinadas a reducir las asperezas creadas por la nueva orientación. De este modo, los contactos con Irán se mantuvieron; abundaron las señales de moderación en la relación con Corea del Norte, y el gobierno de Washington pareció concentrarse sólo en desarrollar consultas con los países árabes acerca del conflicto con Irak, anunciado más que como una acción inmediata, como una inevitable tarea en la agenda. Ahora último, otras señales positivas de moderación, como la resolución adoptada respecto del Medio Oriente, en la que los Estados Unidos concurren al llamamiento en favor de un Estado Palestino, parecen indicar, como tantas otras veces en el pasado, que el juego de los halcones y las palomas forma parte consustancial de la política exterior de Washington.

Los vaivenes entre uno y otro extremo no tienen, sin embargo, su origen en la disputa de corrientes ideológicas. El unilateralismo tiene una raíz más profunda y sistémica, y sus críticos, muy especialmente en Naciones Unidas, parecen, a menudo, olvidar un hecho mayor e insoslayable: la superioridad de los Estados Unidos en el mundo actual.

\section{LA POTENCIA INCONTRARRESTABLE}

Hace pocas semanas, el historiador de Yale y enciclopédico estudioso de imperios, Paul Kennedy, escribía en el Financial Times: "Nunca en la historia ha existido una disparidad de poder como la actual. Jamás. He vuelto a revisar todas las estadísticas de gastos en defensa comparados que compilé para el 'Auge y Caída de los Imperios' durante los últimos 500 años y no hay ninguna nación en la historia que se acerque a los Estados Unidos. La Pax Britannica fue barata en comparación: el ejército bri- 

ción, e incluso la armada británica era igual a las dos que la seguían. El imperio de Carlomagno fue sólo occidental y el romano, si bien se extendía más allá, debía convivir con un imperio Persa y con otro mayor en China... El presupuesto militar de los Estados Unidos de 329 miles de millones de dólares equivale al de los próximos nueve mayores presupuestos militares sumados. El solo incremento solicitado al Congreso de los Estados Unidos por el presidente Bush, de 48 miles de millones de dólares, equivale a dos veces el presupuesto militar anual de Italia..."

Pero Kennedy apunta a un factor aún más decisivo: el financiamiento de este gigantesco esfuerzo militar, a diferencia de los demás imperios, proviene de los recursos propios de la economía americana. Si en 1985 el presupuesto del Pentágono equivalía a un $6.5 \%$ del PGB de los Estados Unidos, y era visto como responsable de las dificultades de crecimiento de la economía norteamericana, en 1998 este presupuesto alcanzaba sólo el 3.2\% de la misma. Ser número uno con un gran costo es una cosa; serlo de manera barata, es otra cosa. Pero aún más: tras las dificultades de los años sesenta, setenta y ochenta, la economía norteamericana ha recuperado e incrementado su distancia respecto de las demás. Los Estados Unidos tienen aproximadamente un 31\% del producto mundial, lo que equivale a la suma de Japón, Alemania, Gran Bretaña y Francia.

Esto le permite desarrollar lo que Robert Nye ha definido como "el poder blando" de los Estados Unidos, es decir, la capacidad de ser paradigmático de la modernidad y generar por lo tanto un modelo a ser imitado universalmente. Hoy, un $45 \%$ del tráfico mundial del internet se desarrolla en ese país; $75 \%$ de los premios Nobel en ciencias, economía y medicina trabajan en los Estados Unidos; un grupo de entre 12 y 15 universidades norteamericanas desarrollan, mediante presupuestos gigantes, una investigación científica que deja en las sombras a todas las universidades europeas y japonesas. Considérese que en el año 2000, 500 mil académicos extranjeros trabajaban en universidades de los Estados Unidos. Si a eso se suma la influencia del cine, la televisión y las comunicaciones en general, se tiene un panorama completo de la superioridad que los Estados Unidos tienen hoy en el mundo. 
Las Naciones Unidas y los Estados Unidos

La superioridad, sin embargo, no es absoluta en todos los planos de la actividad internacional. Los Estados Unidos no pueden conducir y operar en engranajes internacionales que condensan elementos estratégicos, económicos y culturales, sin considerar los intereses de sus aliados y las potencialidades de sus adversarios. La superioridad se hace incontrarrestable, en verdad, sólo en el terreno militar. Los Estados Unidos son el único país del planeta capaz de desplegar misiles nucleares intercontinentales y al mismo tiempo fuerzas convencionales. Pero deja de serlo en el terreno ecónomico, donde el poder es multipolar, con los Estados Unidos, Europa y Japón representando dos tercios del producto mundial y en que China, con su crecimiento dramático, aparece como el cuarto poder. $Y$ en la otra dimensión del poder contemporáneo, las relaciones transnacionales, que escapan al control de los Estados, son eminentemente dispersas e incorporan desde los centros financieros hasta las organizaciones terroristas, los Estados Unidos sólo pueden intervenir asociados a otros Estados. En el escenario que marca la globalización, no parece posible a ningun actor, incluido el principal, obtener todos los resultados que desea para su bienestar y seguridad con el solo recurso de la fuerza militar.

Vuelvo, entonces, al problema de la relación entre las Naciones Unidas y el principal de sus miembros. Éste se reduce a que, mientras la organización tiene problemas para adecuarse a un mundo regido por la superioridad norteamericana, los Estados Unidos tienden, a menudo, a la ilusión de que es posible prescindir del marco multilateral.

\section{LA TAREA DE LAS NACIONES UNIDAS}

Los acontecimientos producidos con posterioridad al 11 de septiembre demuestran a las Naciones Unidas la necesidad de avanzar en un camino de reforma, tanto en lo que se refiere a su comprensión de lo que debe ser la actividad multilateral en el mundo actual, como en sus métodos de trabajo.

Desde un punto de vista político, el desafío no se reduce a evaluar la distancia entre las perspectivas del organismo multilateral y la primera potencia mundial. Dicho de otro modo, la organiza- 
ción debe eludir el esquema conceptual mediante el cual Naciones Unidas representa el antónimo del poder norteamericano. Porque es verdad que mientras las Naciones Unidas constituyen, por definición, el paradigma de la multilateralidad, los Estados Unidos son la máxima expresión del poder unilateral a nivel global. Y también lo es que las Naciones Unidas expresan el máximo grado actual de concesiones colectivas de soberanía nacional, mientras los Estados Unidos representan el bastión más consistente de un concepto de soberanía que, al contrario de los otros Estados naciones, se siente fortalecido por la globalización. Por consiguiente, dada su propia composición y naturaleza, las Naciones Unidas buscan administrar las consecuencias de una globalización esencialmente desequilibrada y dotada de efectos múltiples y contradictorios, mientras que los Estados Unidos intentan conducirla como la proyección de su propio poder.

Pero dichas conclusiones representan sólo una buena base para iniciar una política que debe perseguir reducir la polaridad de los roles y esforzarse por facilitar la inclusión creciente de los Estados Unidos en un esquema de acción multilateral. Para lograrlo, es esencial que los demás miembros de las Naciones Unidas revaloricen ellos mismos su acción multilateral y sean capaces de desarrollarla dentro de los marcos que establece la Carta de la organización y sus instituciones. Los miembros de Naciones Unidas deben ser capaces de mostrar a los Estados Unidos que el unilateralismo puede transformarse en una ilusión y en una mala base de política exterior. Para ello deben abandonar, sin embargo, los intentos de hacer del multilateralismo una práctica de pequeños Estados para entrabar la acción del socio principal, como si los Estados Unidos fueran un Gulliver atrapado entre liliputienses. Hay que alentar a los Estados Unidos a comprender que el marco multilateral es lo más conveniente para sus propios intereses, porque, tal como afirma Joseph Nye: "Estableciendo sus políticas en un marco multilateral, los Estados Unidos pueden hacer de su desproporcionado poder algo más legítimo y aceptable para los demás. Ninguna gran potencia puede permitirse ser puramente multilateral, pero ése debe ser el punto de partida para una política. Y cuando esa gran potencia define su interés nacional de manera tal de incluir intereses globales, algun grado de unilateralismo probablemente es más aceptable para todos". 
Las Naciones Unidas

y los Estados Unidos

Para ello, se hace imprescindible fortalecer el sistema multilateral. En primer lugar, deben multiplicarse los esfuerzos por actuar de manera cada vez más agregada entre los Estados miembros, conformando grupos regionales dinámicos, capaces de identificar e impulsar objetivos viables de carácter global. Este punto es de particular importancia para los países de América Latina, que deben hacer del Grupo de Río su principal mecanismo de participación multilateral. En segundo lugar, deben incrementarse los esfuerzos a nivel nacional destinados a implementar los acuerdos de Naciones Unidas. Los Estados miembros deben ser inducidos a cumplir con lo que suscriben: ése es, en definitiva, el único método eficaz para aumentar el peso del sistema multilateral. Por último, se requiere, dentro de Naciones Unidas, perfilar una agenda de trabajo que remita al tratamiento de los principales temas de interés de la comunidad internacional, reduciendo o eliminando de la agenda aquellos que responden a situaciones obsoletas o intereses periclitados. Si las instituciones de Naciones Unidas, especialmente la Asamblea General, se mantienen fijadas en épocas ya superadas, difícilmente se podrá reclamar la sujeción de los Estados Unidos a prácticas de trabajo colectivo y asociado. Una agenda realista, pero a la vez activa y actualizada, es la mejor manera de establecer un diálogo con la primera potencia mundial que reduzca las tendencias unilaterales y genere un espacio multilateral capaz de absorberlas en un marco colectivo.

En un sistema internacional que se caracteriza crecientemente por preferir coaliciones dinámicas y centradas en problemas específicos más que las antiguas alianzas, de carácter más rígido y permanente, las Naciones Unidas establecen el marco para un diálogo diferente con los Estados Unidos.

Es en Naciones Unidas donde fenómenos como la lucha contra el terrorismo, el narcotráfico, o los esfuerzos por evitar las polarizaciones sociales a que induce la globalización, pueden congregar a grandes grupos de Estados naciones dispuestos a reconocer el papel central que cabe a los Estados Unidos, pero a enfatizar, al mismo tiempo, la necesidad de una acción concertada a nivel multilateral.

Sabemos, sin embargo, que las relaciones de cooperación, de diferenciación y a veces de conflicto entre la primera potencia 
mundial y la principal organización multilateral continuarán en el tiempo, ya que por mucho que las Naciones Unidas sean indispensables para Washington, al encarnar los valores de la democracia, los derechos humanos y el orden jurídico internacional, los Estados Unidos conciben su acción externa antes que nada como una proyección de su propio poder. En realidad, las bases de la cooperación y la diferenciación están en la naturaleza misma del poder que ellos encarnan, por lo que ambos se intercalarán permanentemente. Pero radica en el poder de los miembros de Naciones Unidas renovar el sistema multilateral y adecuarlo a las características del mundo actual, de tal manera de hacer del compromiso multilateral de la primera potencia mundial una práctica necesaria a sus intereses. 